\title{
RELAÇÕES ÉTNICO-RACIAIS E 0 ENSINO DE CIÊNCIAS: UM MAPEAMENTO DAS PESQUISAS SOBRE 0 TEMA
}

\author{
Jeobergna de Jesus (UFSB)* \\ Marília Costa Santos da Paixão (UESC)** \\ https://orcid.org/0000-0002-4271-4533 \\ Christiana Andrea Vianna Prudêncio (UESC) ${ }^{* * *}$ \\ https://orcid.org/0000-0002-4571-2090
}

\section{RESUMO}

0 presente artigo realiza um levantamento sobre quais aspectos das relações étnico-raciais e o ensino de ciências tem sido evidenciados nas pesquisas em Educação em Ciências, tendo como base as atas de um dos maiores eventos da área no Brasil, o Encontro Nacional de Pesquisa em Educação em Ciências (ENPEC). Essa necessidade surge de cumprir demandas sociais históricas, reforçadas pela promulgação da Lei no $10.639 / 03$, que torna obrigatória a abordagem da história e cultura africana e afro-brasileira em todas as disciplinas. Contudo, a literatura aponta que a área de Ciências carece de discussões sobre essas questões. Com o objetivo de traçar um panorama das pesquisas sobre educação em Ciências e sua interface com as relações étnico-raciais, analisamos as atas do ENPEC de 2003 a 2015. Os resultados demonstraram que dentre as categorias que elencamos para classificar as pesquisas (concepções de alunos e professores, ensino, formação inicial e continuada de professores e material didático) destaca-se a produção em ensino e material didático. Além disso, é notada a necessidade de mais pesquisas que atentem para a elaboração de estratégias para a inserção das discussões sobre as relações étnico-raciais nas aulas de Ciências. As pesquisas mostram ainda que a área de Ciências é a que mais possui produção, seguida da Biologia e da Química. No entanto, nenhum trabalho foi encontrado na área da Física. Os temas mais comumente pesquisados são: a formação de professores, com o objetivo de pensar práticas para as discussões raciais e o ensino de Ciências. Evidenciamos assim que as relações étnico-raciais precisam ser mais contempladas no ensino de Ciências, pois mesmo que a Lei $\mathrm{n}^{\mathrm{0}}$ 10.639/03 as tenha tornado obrigatórias, ainda existe uma série de dificuldades para seu efetivo cumprimento, dentre elas a falta de

Doutoranda do Programa de Pós-Graduação Estado e Sociedade da Universidade Federal do Sul da Bahia (UFSB). Docente da Escola Estadual Antônio Carlos Magalhães e do Colégio Cariza, em Porto Seguro, Bahia. E-mail: jeobergna.jesus@gmail.com

** Mestre em Educação em Ciências pela Universidade Estadual de Santa Cruz (UESC). Docente do Centro Estadual de Educação Profissional do Chocolate Nelson Schaun, em Ilhéus, Bahia. E-mail: mariliacsbio@gmail.com

*** Doutora em Educação pela Universidade Federal de São Carlos (UFSCar). Docente da Universidade Estadual de Santa Cruz (UESC). E-mail: christiana.ead@gmail.com 
materiais didáticos específicos e as limitações que os docentes possuem para incorporar essa temática em suas disciplinas.

Palavras-chave: Lei no 10.639 . Pesquisa em educação em ciências. Relações étnico-raciais.

\section{ABSTRACT}

\section{ETHNIC-RACIAL RELATIONS: A BRIEF MAPPING ON THE THEME IN THE CONTEXT OF RESEARCH IN EDUCATION IN SCIENCES}

This article presents a survey of which aspects of ethnic-racial relations and the teaching of science have been evidenced in the researches in Education in Sciences, based on the minutes of one of the major events of the area in Brazil, the National Meeting of Education in Sciences (ENPEC). This need arises from fulfilling historical social demands, reinforced by the enactment of Law no 10.639/03, which makes it necessary to approach African and Afro-Brazilian history and culture in all disciplines. However, the literature points out that the area of science lacks discussions on these issues. With the objective of outlining the research on science education and its interface with ethnic-racial relations, we analyzed the ENPEC minutes from 2003 to 2015. The results showed that among the categories we list to classify the researches (student conceptions and teachers, teaching, initial and continuing training of teachers and didactic material), we highlight the production in teaching and didactic material, in addition it is noticed the need for more research that is attentive to the elaboration of strategies for insertion of the discussions about the relations racial classes in science classes. Research also shows that the area of science is the one with the most production, followed by biology and chemistry. However, no work was found in the area of Physics. The most commonly researched themes are: teacher training, with the aim of thinking about practices for racial discussions and the teaching of science. We thus show that ethnic-racial relations need to be more contemplated in science education, because although Law no 10.639/03 makes them compulsory, there are still a number of difficulties for its effective fulfillment, among them the lack of specific didactic materials and difficulties teachers have in incorporating this theme in their disciplines.

Keywords: Law $\mathrm{n}^{\circ}$ 10.639. Research in education in sciences. Ethnic-racial relations.

\section{RESUMEN}

\section{RELACIONES ÉTNICO-RACIALES Y ENSEÑANZA DE LAS CIENCIAS: UN MAPEO DE INVESTIGACIONES SOBRE EL TEMA}

El presente artículo realiza un relevamiento sobre cuáles aspectos de las relaciones étnico-raciales y la enseñanza de las ciencias han sido evidenciados en las investigaciones en Educación en Ciencias, teniendo como base las actas de uno de los mayores eventos del área en Brasil, el Encuentro Nacional de Educación en Ciencias (ENPEC). Esta necesidad surge de satisfacer demandas 
sociales históricas, reforzadas por la promulgación de la Ley no 10.639/03 que hace obligatoria el abordaje de la historia y cultura africana y afro-brasileña en todas las disciplinas. Sin embargo, la literatura apunta que el área de Ciencias carece de discusiones sobre esas cuestiones. Con el objetivo de trazar un panorama de las investigaciones sobre educación en Ciencias y su interfaz con las relaciones étnico-raciales, analizamos las actas del ENPEC de 2003 a 2015. Los resultados demostraron que entre las categorías que elencamos para clasificar las investigaciones (concepciones de alumnos y profesores, enseñanza, formación inicial y continuada de profesores y material didáctico) se destaca la producción en enseñanza y material didáctico, además es notada la necesidad de más investigaciones que se atente a la elaboración de estrategias para inserción de las discusiones sobre las relaciones étnico-raciales en las clases de Ciencias. Las investigaciones muestran además que el área de las Ciencias es la que más posee producción, seguida de la Biología y la Química. Sin embargo, no se encontró ningún trabajo en el área de la física. Los temas más comúnmente investigados son: la formación de profesores, con el objetivo de pensar prácticas para las discusiones raciales y la enseñanza de las ciencias. En el caso de las relaciones étnico-raciales, las relaciones étnico-raciales deben ser más contempladas en la enseñanza de las ciencias, pues a pesar de la Ley $\mathrm{n}^{\mathbf{0}}$ 10.639/03 hacerlas obligatorias todavía existe una serie de dificultades para el efectivo cumplimiento de la misma, entre ellos la falta de materiales didácticos específicos y, dificultades que los docentes poseen en incorporar esa temática en sus disciplinas

Palabras clave: Ley no 10.639. Investigación en educación en ciencias. Relaciones étnico-raciales.

\section{Porque falar sobre relações étnico-raciais}

Atualmente nos deparamos com acontecimentos que têm provocado debates sobre o racismo. Os meios de comunicação demonstram situações em estádios de futebol, nas redes sociais etc. nas quais pessoas foram humilhadas e até agredidas por pertencerem à determinada etnia. Infelizmente, estes episódios são apenas uma pequena parcela de todas as situações constrangedoras e, importante ressaltar, ilegais que diversos brasileiros sofrem diariamente por conta do preconceito, o que demonstra a necessidade de mais discussões sobre as relações étnico-raciais em diferentes espaços e, inclusive nas pesquisas educacionais.

Vivemos em um contexto importante para o combate ao racismo, uma vez que as discussões sobre as relações étnico-raciais têm acontecido de maneira mais aberta. Essa abertura é oriunda, em parte, de mobilizações do Movimento Negro e de ações que ocorreram internacionalmente, como, por exemplo, a III Conferência Mundial contra o Racismo, Discriminação Racial, Xenofobia e Intolerância Conexa que ocorreu em Durban, na África do Sul. Esse evento, aliado às contribuições do Movimento Negro, culminaram na elaboração de textos legais destinados à área da educação, como o Parecer CNE no 1 (BRASIL, 2004), que alterou a Lei no 9.394/96, Lei de Diretrizes e Bases da Educação Nacional, por meio da Lei no 10.639/03 (BRASIL, 2003), que caracteriza a obrigatoriedade do ensino da história africana e afrodescendente no currículo da Educação Básica (VERRÂNGIA, 2009). 
Vale ressaltar, porém, que essas mudanças foram demasiadamente postergadas, pois desde o início do século XX os afrodescendentes reivindicam que o Estado adote medidas de reparação à violência sofrida no período da escravidão, bem como às desigualdades sociais que até hoje marcam o povo negro. Essas marcas estiveram presentes, por exemplo, na história do sistema educacional brasileiro, que além de não se destinar a todos, se pautava em uma educação eurocêntrica baseada em políticas eugênicas e higienistas que não contemplavam a população indígena e negra (VERRÂNGIA, 2009).

Nesse sentido, propostas e discussões para o ensino das relações étnico-raciais devem existir, sobretudo, nas escolas, geralmente o primeiro lugar onde crianças negras aprendem que o racismo existe (SOUZA, 2001). Por esse motivo a promulgação da Lei no $10.639 / 03$ (BRASIL, 2003) é um passo importante para a mudança desse cenário, pois, mesmo de maneira tímida, tem iniciado a abertura de discussões sobre as relações étnico-raciais no espaço escolar, o que se configura um esforço rumo à diminuição ou até à erradicação do preconceito racial.

A Lei supracitada determina que essas discussões devem ocorrer em todas as disciplinas, mas ainda existe a crença de que as relações étnico-raciais são responsabilidade dos professores de História, Geografia e Letras, ou ainda que esta discussão deva ser conduzida somente por professores negros e/ou militantes. Contudo, a lei não faz distinção de disciplinas e, no caso específico de Ciências e Biologia, não é possível ignorar o fato de que no passado os conteúdos dessas áreas de conhecimento foram largamente utilizados para justificar e até consolidar o racismo.

Assim, no entendimento de que a produção acadêmica e científica revela o quanto os especialistas e pesquisadores têm se debruçado para discutir essas importantes questões, esta pesquisa possui o objetivo de traçar um panorama das pesquisas sobre educação em Ciências e sua interface com as relações étnico-raciais.

A problematização da abordagem dessas relações nas pesquisas que vêm sendo desenvolvidas é importante porque o racismo é "uma rejeição da diferença; pela recusa, incapacidade ou impossibilidade de aceitar o que é diferente, o que não é idêntico" (SILVA, 2009, p. 11), e isso, urgentemente, precisa ser superado.

A forma como essa temática é tratada nas pesquisas é também um caminho para divulgar algumas das maneiras pelas quais as questões étnico-raciais vêm sendo trabalhadas no espaço escolar. Olhar para tais discussões na escola se justifica por dois motivos: primeiro porque esta deve se posicionar para a implementação de uma educação pautada no respeito às diferenças étnico-raciais e no atendimento da Lei no 10.639/03 (BRASIL, 2003); segundo, porque um dos maiores motivos pelos quais os professores não trabalham as relações étnico-raciais em suas aulas é, segundo eles, o desconhecimento sobre como fazê-lo (COELHO; SOARES, 2015).

Um dos caminhos que possibilitam a reflexão crítica sobre as questões supracitadas é a incorporação do ensino da cultura de todos os povos que constituem o Brasil, uma vez que a proposta não é substituir a educação eurocêntrica por outra, africana, mas possibilitar que todos esses conhecimentos sejam abordados no ambiente escolar de maneira que sensibilize a população sobre o quão necessário é respeitar as diferenças étnico-raciais e o reconhecimento da história do povo negro para além da escravidão.

Retomando a responsabilidade do ensino de Ciências em combater o preconceito e a discriminação, entendemos que se ele for acrítico proporcionará a manutenção do racismo, uma vez que ele "incorpora uma forma de propaganda racista sutil, difícil de ser detectada, principalmente tendo em vista que essa forma de conhecimento é comumente percebida como politicamente neutra" (VERRÂNGIA, 2009, p. 12). Essa pseudoneutralidade ajuda a mascarar 
o racismo científico que ainda existente e que precisa ser superado para a promoção de um ensino de Ciências convergente com a Lei $\mathrm{n}^{0}$ 10.639/03 (BRASIL, 2003), e de uma ciência que não tenha mais seus conceitos e conhecimentos utilizados para a discriminação, de qualquer natureza.

\section{As relações étnico-raciais e o ensino de ciências}

Depois de sofrer diversas transformações ao longo do tempo, no que diz respeito a suas metodologias e função social, o ensino de Ciências no Brasil atualmente se preocupa em formar alunos críticos, que entendam e problematizem o papel da ciência e da tecnologia em suas vidas. Isso perpassa necessariamente uma educação voltada para atender à diversidade encontrada nas salas de aula (AZEVEDO; ABIB, 2013), na qual seja possível discutir que "as contradições culturais, econômicas e sociais atingem os sujeitos sociais em suas vidas, em seus objetivos, em seus cotidianos" (DÁVILA, 2005, p. 86). Só abordando sistematicamente essas questões será possível dizer que o ensino de Ciências cumpre uma de suas funções, a de formar para cidadania.

Um dos caminhos possíveis para que o ensino de Ciências se comprometa com a promoção de uma educação cidadã é a inserção das discussões das relações étnico-raciais. Dávila (2005) sinaliza que o debate sobre as relações étnico-raciais nos ambientes escolares e nos cursos de formação de professores é fundamental porque a cultura da população menos favorecida, econômica ou racialmente, tem sido completamente esquecida ou simplesmente apresentada de maneira equivocada. Com isso, o autor acrescenta ainda que "os desafios postos, nesse século, são múltiplos e os profissionais da educação que trabalham nos cursos de formação de professores não podem mais fechar os olhos para esses desafios que nos apresentam" (DÁVILA, 2005, p. 91).
Portanto, para que a discussão das relações étnico-raciais na escola aconteça, um ator importante no processo deve ser levado em conta: o professor, sendo fundamental investigar em que medida sua formação tem permitido que ele conduza essas discussões de maneira positiva e comprometida com a formação para cidadania, o que perpassa o combate a todo o tipo de preconceito. Para tanto, é necessário que os docentes superem a visão simplista do ensino de Ciências, ou seja, pautada somente na transmissão de conhecimentos científicos aparentemente neutros, acríticos e a-históricos, que nem interferem e nem sofrem interferência de fatores sociais, econômicos e políticos.

Um exemplo das interferências da sociedade na construção do conhecimento científico está na forma como este passa a discutir as relações étnico-raciais em pesquisas pioneiras, como a realizada pelo Grupo de Trabalhos para Assuntos Afro-Brasileiros (GTAAB), que buscou investigar como o ensino de Ciências poderia abordar essa temática, especificamente com relação aos conhecimentos de Biologia para o combate ao racismo, embasados na discussão do conceito biológico de raça, amplamente utilizado para justificar a hierarquia entre as "raças humanas", conduzindo à própria justificativa da escravidão. Para o Grupo, seria necessário que o sistema escolar brasileiro e, principalmente, o ensino de Ciências se pautassem em uma abordagem antirracista. Porém,

Frente a essa necessidade de produzir um ensino de Ciências que, efetivamente, se comprometa com o combate ao racismo, encontra-se uma ausência quase total de orientações específicas, tanto formuladas por parte do governo quanto da literatura em educação e ensino de Ciências no Brasil. Essa ausência não impede a busca por compreender como a legislação vigente e a literatura na área contribuem, ou não, para o desenvolvimento de tal ensino. Essa compreensão passa, necessariamente, pela discussão das relações entre ensino de Ciências e cidadania. (VERRÂNGIA, 2009, p. 14).

A Lei $\mathrm{n}^{\circ}$ 10.639/03 preconiza que todas as disciplinas devem se comprometer com a 
abordagem das relações étnico-raciais, regulamentando a implantação de dois artigos a Lei de Diretrizes e Bases da Educação Nacional (LDB): o artigo 26A, que traz a obrigatoriedade dos conhecimentos da cultura africana e afrodescendente e da história da África na educação básica, e o 79B, que insere no calendário escolar o Dia Nacional da Consciência Negra (BRASIL, 2003).

Com esse dispositivo legal é possível chamar a atenção da sociedade para o fato de que não basta garantir apenas o acesso dos negros às escolas, é necessário também valorizar e reconhecer a cultura e história africana e afrodescendente, com o intuito de reparar danos, criar uma identificação positiva de alunos negros com seus antepassados e compreender que "estudos referentes à cultura afro-brasileira, não dizem respeito apenas à população negra, mas sim a todos (as) os (as) brasileiros (as)" (JESUS, 2013, p. 162).

Coelho e Soares (2015) apresentam alguns entraves para que se estabeleça o ensino das relações étnico-raciais no ensino básico, como, por exemplo, a falta de formação dos professores nessa perspectiva e a ausência de materiais didáticos apropriados, a exemplo de livros didáticos que nem sempre auxiliam para que esse objetivo possa ser alcançado, seja porque silenciam sobre a cultura africana, seja porque ainda não conseguem apresentar uma visão dos negros no Brasil, a não ser pelo viés da escravidão. Como dito anteriormente, uma das dificuldades para a implantação efetiva da Lei $n^{0}$ 10.639/03 está centrada na formação de professores, que não deve ser restrita apenas à aquisição de conhecimentos técnicos e pedagógicos, incluindo também a inserção de temáticas sociais como a questão racial, foco de nossa pesquisa, para que então essa discussão chegue à escola de maneira mais efetiva, uma vez que o ambiente escolar é 'lócus de encontro da diversidade social e cultural de nossa sociedade" (JESUS, 2013, p. 47).

A Resolução CNE n² 2, de 2015 (BRASIL, 2015), que define as Diretrizes Curriculares
Nacionais para a formação inicial e continuada de professores, busca uma mudança de pensamento no que diz respeito às discussões sobre as relações étnico-raciais nesses espaços de formação. Com isso o objetivo central é estabelecer diretrizes curriculares que tratem de orientações e princípios e não somente procedimentos pedagógicos para aplicabilidade da Lei, e que se foquem na necessidade de mudança da postura e forma de pensar dos formadores de professores e futuros docentes. A validade da existência de leis e diretrizes que conduzam à presença da discussão sobre as diferenças étnicas em sala de aula é sem dúvida inquestionável, porém devemos considerar primeiramente, que:

Apesar da complexidade da luta contra o racismo, que consequentemente exige várias frentes de batalha, não temos dúvidas de que a transformação de nossas cabeças de professores é uma tarefa preliminar importantíssima. Essa transformação fará de nós os verdadeiros educadores, capazes de contribuir no processo de construção da democracia brasileira, que não poderá ser plenamente cumprida enquanto perdurar a destruição das individualidades históricas e culturais das populações que formaram a matriz plural do povo e da sociedade brasileira. (MUNANGA, 2005, p. 17).

Notamos que os professores apresentam dificuldades em discutir as relações étnico -raciais por diversos motivos: alguns não se sentem responsáveis por conduzir o debate por não serem negros ou, ainda, por não conseguirem visualizar em suas áreas de conhecimento e disciplinas possibilidades de conexão entre as relações étnico-raciais. Isso acontece com certa frequência quando se trata, por exemplo, do ensino de Ciências, como foi evidenciado por Jesus, Santos e Prudêncio (2016), que realizaram uma pesquisa com professores de Ciências de escolas estaduais do interior da Bahia. Foi perguntado aos professores se acreditavam que conseguiriam implantar em suas aulas as discussões sobre relações étnico-raciais e, de maneira mais específica, se poderiam sinalizar algum conhecimento de matriz africana e afro- 
descendente que tivesse relação com o ensino de Ciências. A maioria dos professores revelou que essa proposta era difícil de ser executada por conta da falta de formação adequada para conduzir essas discussões e por não conseguirem imaginar de que forma os conhecimentos científicos poderiam se relacionar a essa temática. Porém, é importante lembrar que as Ciências, que já tiveram um importante papel na manutenção do racismo, hoje têm igual papel em sua desconstrução, isso porque "Os saberes da biologia molecular dizem, um a um, sem exceção, exatamente o contrário de tudo aquilo que os racistas vêm, através dos tempos, usando como se fosse a favor de sua doutrina. 0 racismo repousa, pois, sobre uma mentira incomensurável." (OLIVEIRA, 2003, p. 56).

Outro fator relevante a ser mencionado diz respeito à organização dos currículos tanto da educação básica quanto dos cursos de formação de professores, que poderão permitir ou não que os assuntos referentes à diversidade étnico-racial sejam abordados.

Verrângia (2009) apresenta, a partir dos resultados de sua pesquisa, relações entre Ciências Naturais, conhecimento científico, ensino de Ciências e relações étnico-raciais, mostrando ser possível a discussão dessa temática nas aulas de Ciências. Em outro trabalho, Verrângia e Silva (2010) apresentam alguns elementos estratégicos para que essas relações sejam estabelecidas no ensino de Ciências, elaborando cinco grupos temáticos e questões que orientam nessa perspectiva:

a) Impacto das Ciências Naturais na vida social e racismo; b) superação de estereótipos, valorização da diversidade e Ciências Naturais; c) África e seus descendentes e o desenvolvimento científico mundial; d) Ciências, mídia e relações étnico-raciais, e) conhecimentos tradicionais de matriz africana e afro-brasileira e Ciências. (VERRÂNGIA; SILVA, 2010, p. 707).

Ainda que a Lei no 10.639/03 (BRASIL, 2003) seja uma ação afirmativa para a população negra, a qual permite legitimar e valorizar a história desse grupo étnico, somente sua existência não fará com que mudanças ocor- ram. Por isso é preciso buscar estratégias bem fundamentadas para a inserção dos conhecimentos de matriz africana e afrodescendente em todo o currículo escolar e não somente em algumas disciplinas, de forma, muitas vezes, pontual.

Considerando que alguns autores, como Verrângia (2009), Bastos e Benite (2017) e Rosa (2016), já sinalizaram que o ensino de Ciências precisa adentrar nesse campo de discussões de maneira mais significativa, buscando estratégias para a inserção da temática especificamente nessa área de conhecimento, e entendendo que esse feito perpassa necessariamente o desenvolvimento de pesquisas em Educação em Ciências, nesse sentido, buscamos fazer um panorama de como essas pesquisas vêm sendo desenvolvidas em um dos maiores eventos da área de Educação em Ciências.

\section{Da seleção dos artigos à análise dos dados}

Na busca por realizar uma revisão bibliográfica sobre as pesquisas que têm como foco as relações étnico-raciais e o ensino de Ciências, Química, Física e Biologia, procuramos identificar os artigos publicados no Encontro Nacional de Pesquisa em Educação em Ciências (ENPEC). Essa escolha justifica-se por este ser um dos maiores eventos de pesquisa na área de educação em Ciências e, portanto, abranger trabalhos das mais diversas regiões do Brasil e representar, em parte, o que de mais relevante vem sendo produzido na área.

O ENPEC é um evento bianual e nossa faixa de tempo compreende os anos de 2003 á 2015 por conta da data da promulgação da Lei $\mathrm{n}^{\mathrm{o}}$ 10.639/03 (BRASIL, 2003). Dessa maneira, conseguimos traçar um panorama sobre a representatividade das pesquisas relativas às relações étnico-raciais na área de educação em Ciências, ao mesmo tempo em que analisamos em que medida essa temática é discutida nesses trabalhos, buscando compreender qual enfoque tem sido dado a essa problemática. 
Os trabalhos foram levantados nas atas de cada ENPEC disponíveis no site da Associação Brasileira de Pesquisa em Educação em Ciências - ABRAPEC (2017). Procuramos por artigos apresentados tanto na modalidade oral quanto na forma de painéis, e os descritores utilizados para selecionar os trabalhos foram: Lei 10.639, raça, racismo, relações étnico-raciais, etnia, diversidade e multiculturalismo. Escolhemos estes termos porque em pesquisas que abordam as questões étnico-raciais pelo menos um deles está presente no título, resumo ou palavras-chave.

Os termos que utilizamos para fazer as buscas nos permitiram também entrar em contato com trabalhos que não discutem as relações étnico-raciais como, por exemplo, ao utilizar o termo "raça", encontramos um trabalho intitulado Raça ou espécie? Relações interpessoais em sala de aula (PEDRANCINI; CORAZZA, 2011), publicado no VIII ENPEC. Contudo, não o analisamos, uma vez que a pesquisa não é feita com seres humanos e, portanto, longe do escopo de nossa pesquisa.

Primeiramente, empregamos os termos descritos anteriormente nos títulos, palavras-chave e resumos, e assim agrupamos os trabalhos segundo sua área, o que nos conduziu à formação das categorias: a) concepções; b) ensino; c) formação de professores; d) material didático. 0 estabelecimento dessas categorias nos aju- dou a compreender como estão distribuídos os trabalhos dentro do campo de pesquisa da educação em Ciências.

Posteriormente, fizemos a leitura na íntegra dos trabalhos previamente selecionados e categorizados, de modo a podermos discutir mais detalhadamente aspectos referentes às relações étnico-raciais e sua abordagem dentro de cada uma das categorias.

\section{0 que as pesquisas apontam}

Nos eventos do ENPEC analisados ao longo desses 12 anos, observamos que as produções sobre as questões étnico-raciais oscilam bastante, uma vez que em alguns anos esse tema é contemplado, mas em outros simplesmente desaparece.

O levantamento foi realizado de 2003 a 2015 , resultando num total de 6.148 trabalhos apresentados. Deste montante, 16 trabalhos (aproximadamente 0,3\%) tiveram como propósito discutir as relações étnico-raciais (RER) no ensino de Ciências. Diante da grande dimensão que o evento possui, tais números, a nosso ver, corroboram o que é apresentado em outras pesquisas (BASTOS; BENITE, 2017; GOMES; ROSA, 2015; VERRÂNGIA, 2009) que indicam uma lacuna em relação ao desenvolvimento de trabalhos em educação em Ciências que contemplem as relações étnico-raciais.

Tabela 1 - Número total de trabalhos apresentados e dos que contemplam a temática das relações étnico-raciais do IV ao X ENPEC

\begin{tabular}{cccc}
\hline EVENTO & ANO & $\begin{array}{c}\text { No DE TRABALHOS } \\
\text { APRESENTADOS }\end{array}$ & $\begin{array}{c}\text { No DE TRABALHOS SOBRE } \\
\text { RELAÇÕES ÉTNICO-RACIAIS }\end{array}$ \\
\hline IV ENPEC & 2003 & 451 & 0 \\
V ENPEC & 2005 & 738 & 1 \\
VI ENPEC & 2007 & 669 & 1 \\
VII ENPEC & 2009 & 723 & 0 \\
VIII ENPEC & 2011 & 1.235 & 1 \\
IX ENPEC & 2013 & 1.060 & 9 \\
X ENPEC & 2015 & 1.272 & 4 \\
\hline Total & & 6.148 & 16 \\
\hline
\end{tabular}

Fonte: Elaborado pelos autores deste artigo. 
Ao observar a Tabela 1 podemos notar um aumento de trabalhos apresentados no IX ENPEC envolvendo a temática. Esse aumento significativo provavelmente se deve aos dez anos da promulgação da Lei no $10.639 / 2003$ (BRASIL, 2003), pois todos os nove trabalhos apresentados neste ano fazem referência à Lei, sendo o trabalho de Moreira, Amauro e Rodrigues
Filho (2013), por exemplo, dedicado a fazer um levantamento dos dez anos de sua promulgação.

\section{Concepções}

Nessa categoria estão reunidos os trabalhos que abordaram concepções discentes e docentes sobre as relações étnico-raciais.

Quadro 1 - Trabalhos sobre concepções (discente/docente) com a temática étnico-racial no ensino de Ciências, Química, Física e/ou Biologia

\begin{tabular}{|c|c|c|l|c|}
\hline EVENTO & ANO & $\begin{array}{c}\text { ORIGEM DAS } \\
\text { CONCEPÇ0̃ES }\end{array}$ & TÍTULO & AUTOR(ES) \\
\hline V ENPEC & 2005 & Discentes & $\begin{array}{l}\text { Diferenças raciais: o que diz a biologia, o } \\
\text { que pensam os alunos }\end{array}$ & Vieira e Chaves \\
\hline IX ENPEC & 2013 & $\begin{array}{l}\text { Coordenação } \\
\text { pedagógica }\end{array}$ & $\begin{array}{l}\text { O discurso da coordenação pedagógica da } \\
\text { rede de ensino do município de Vicência } \\
\text { sobre a noção de "raça" }\end{array}$ & Melo \\
\hline IX ENPEC & 2013 & Docentes & $\begin{array}{l}\text { Preconceito étnico-racial: a escola, a } \\
\text { Ciência e a formação de professores }\end{array}$ & Carlan e Dias \\
\hline
\end{tabular}

Fonte: Elaborado pelos autores deste artigo.

Os três trabalhos mostram a importância do embasamento teórico sobre conceitos como raça e preconceito como ponto de partida para se desconstruir concepções equivocadas e construir novas, tanto por parte de alunos quanto de professores.

Um trabalho que evidencia diferentes concepções raciais é o de Vieira e Chaves (2005), realizado em uma aula de Biologia de uma escola particular, verificando as concepções de 27 alunos sobre as diferenças raciais. Aos alunos foram colocadas as seguintes questões: 0 que é raça?; qual é a sua raça?; o que você acha das ações afirmativas?

Esses questionamentos deram início a um curto debate e a partir daí foi solicitado aos alunos uma dissertação sobre o tema raça. Com esses dados em mãos os autores afirmam que os alunos trazem argumentos próximos aos que estão estabelecidos pelos conhecimentos científicos atuais, ou seja, que não existem diferenças biológicas que justifiquem a existência de diferentes raças humanas, não havendo, portanto, raças su- periores e inferiores.

A respeito disso, Oliveira (2003) aborda que a contribuição do Projeto Genoma Humana (PGH) e do Projeto de Diversidade do Genoma Humano (PDGH) foram relevantes para a finalização da concepção de que existiam raças superiores e melhores. Porém, vale ressaltar que esse argumento por si só não quer dizer que as cotas e outras ações afirmativas são desnecessárias.

Outro elemento que o autor traz de relevante em sua pesquisa é a dificuldade de a maioria dos alunos se autodenominarem negros, não negros, pardos e indígenas. Os alunos justificam essa dificuldade porque acreditam que existem vários tipos de brancos, negros e pardos. Podemos inferir que um dos fatores que dificultam a autodenominação dos alunos como negros pode estar relacionado às imagens negativas sobre os negros que a mídia constrói, e a escola silencia ou mostra sempre associado à escravidão.

Em outro trabalho, Melo (2013) apresenta uma discussão sobre a noção de "raça" na rede 
de ensino do município de Vicência (PE), trabalhando a importância do entendimento dos professores que atuam na coordenação pedagógica de que o termo raça não mais se aplica à explicação da diversidade humana. Esse trabalho foca na coordenação pedagógica, uma vez que ela agrega profissionais que também são responsáveis pela formação de professores, e suas práticas e discursos os influenciam. Destacamos que saber o conceito de raça não é suficiente para o término do racismo, pois essa ideia de que existem raças na espécie humana ainda está presente no imaginário das pessoas.

Em nossa análise, o trabalho de Carlan e Dias (2013) corrobora o de Melo (2013) ao enfatizar que alguns docentes de Ciências e de Biologia apresentam dificuldades para trabalhar com as relações étnico-raciais em suas aulas e que para superar tal obstáculo é importante conhecer as concepções de seus alunos sobre o que é raça, etnia e relações étnico-raciais, visto que a partir desse conhecimento os professores podem trilhar um caminho que conduza a uma educação cidadã pautada no respeito às diferenças e valorização das diferentes etnias. A pesquisa foi feita com 19 alunos do Ensino Médio do turno noturno de uma escola pública de Pelotas (RS), que responderam a um questionário com 17 perguntas, as quais buscavam entender o pertencimento étnico-racial de cada aluno, a escolaridade deles e de seus familiares e, por fim, como eles enxergavam os negros na sociedade.

Como resultado a pesquisa mostrou que dos 19 alunos, 11 se declararam brancos e 8, negros. Os autores destacam que no momento da aplicação do questionário muitos alunos sentiram dificuldades de se definirem como negros. Carlan e Dias (2013) atribuem essa dificuldade à desqualificação do perfil do negro oriundo do processo histórico de discriminação. Um fato intrigante do resultado da pesquisa foi a ausência do conhecimento sobre cotas por parte de todos os estudantes. Após a explicação da política de cotas pela professora responsável pela turma, 53\% dos alunos afirmaram serem a favor das cotas e $47 \%$ de posicionaram contrários.

Guimarães (2003) ajuda a entender a dificuldade de os alunos se declararem como negros abordando a desvalorização estética e histórica do povo negro, propagada mediante a visão recorrente dos negros em situações desfavoráveis e de escravidão, sem levar em consideração sua participação na ciência, letras, artes, comércio, indústria etc. Verrângia e Silva (2010) defendem a valorização de personalidades africanas e afrodescendentes que contribuíram para a construção da Ciência, ampliando a chance de que os alunos negros se sintam representados de maneira positiva.

\section{Ensino}

Nesta categoria reunimos todos os trabalhos apresentados no ENPEC de 2003 a 2015 que problematizam o ensino das relações étnico -raciais no ensino de Ciências, Química, Física e Biologia.

Quadro 2 - Trabalhos sobre ensino de Ciências, Química, Física e/ou Biologia com a temática étnico-racial

\begin{tabular}{|c|c|l|c|}
\hline EVENTO & ANO & \multicolumn{1}{|c|}{ TÍTULO } & AUTOR(ES) \\
\hline \multirow{2}{*}{ VIII ENPEC } & 2011 & $\begin{array}{l}\text { A Bioquímica do Candomblé - possibilidades didáticas de } \\
\text { aplicação da Lei Federal 10.639/03 }\end{array}$ & $\begin{array}{c}\text { Moreira e } \\
\text { colaboradores }\end{array}$ \\
\hline \multirow{2}{*}{ IX ENPEC } & 2013 & $\begin{array}{l}\text { Desvendando a Anemia Falciforme - Uma proposta lúdica } \\
\text { para aplicação da Lei Federal 10.639/03 }\end{array}$ & $\begin{array}{c}\text { Moreira e } \\
\text { colaboradores }\end{array}$ \\
\cline { 3 - 5 } & & $\begin{array}{l}\text { O filme “Jardim das Folhas Sagradas” e a possibilidade de } \\
\text { uma abordagem intercultural em aulas de Ciências }\end{array}$ & $\begin{array}{c}\text { Oliveira, Trindade } \\
\text { e Queiroz }\end{array}$ \\
\hline \multirow{2}{*}{ X ENPEC } & 2015 & $\begin{array}{l}\text { Raça, classe e etnia: o ensino das ciências na educação } \\
\text { básica }\end{array}$ & $\begin{array}{c}\text { Tonácio e } \\
\text { colaboradores }\end{array}$ \\
\cline { 2 - 5 } & & $\begin{array}{l}\text { Estudos do racismo científico e da sociedade: perspectivas } \\
\text { para a ação em ensino de ciências }\end{array}$ & $\begin{array}{c}\text { Castillo e } \\
\text { Andrade }\end{array}$ \\
\hline
\end{tabular}

Fonte: Elaborado pelos autores deste artigo. 
Os trabalhos elencados revelam o esforço que tem sido feito em determinadas disciplinas para discutir em alguma medida questões étnico-raciais em sala de aula. Assim, de modo geral, são pesquisas que apresentam propostas utilizadas nas escolas para abordar essa temática, sendo que algumas problematizam o quanto a promulgação da Lei no 10.639/03 (BRASIL, 2003) realmente impactou na promoção do ensino das relações étnico-raciais. Esses trabalhos vão ao encontro do que Verrângia (2009) discute ao mostrar que, apesar das dificuldades, é possível discutir relações no ensino de Ciências.

Destacamos o trabalho de Santos, Siemsen e Silva (2015), que discute o racismo, a influência das pesquisas científicas para a "validação" do racismo e o quanto são necessários esforços para superar o racismo científico impregnado no ensino das Ciências. Dessa forma, é estabelecida uma convergência desta pesquisa com a de Oliveira (2003), que enfatiza que os conhecimentos produzidos pela biologia molecular invalidam todos os argumentos utilizados pelos racistas e, portanto, a própria ciência precisa se retificar. Todavia, ao mesmo tempo, é imprescindível destacar que ainda que sejamos todos iguais biologicamente, as condições de acesso à saúde, à educação e à cultura, entre outros, não é a mesma para as diferentes etnias.

\section{Formação de professores}

Dos trabalhos encontrados no ENPEC três eram sobre formação de professores: dois com enfoque na formação inicial e um na formação continuada. Todas as pesquisas sinalizam que é necessário inserir no processo formativo docente a discussão das relações étnico-raciais, como defende Jesus (2013), que aponta ainda que o cumprimento da Lei no 10.639/03 (BRASIL, 2003) só será realmente efetivado nas escolas, quando os professores forem formados nessa perspectiva, debatendo sobre conceitos de raça, racismo, diversidade, entre outros.

Quadro 3 - Trabalhos sobre formação de professores (inicial/continuada) com a temática étnico-racial no ensino de Ciências, Química, Física e/ou Biologia

\begin{tabular}{|c|c|c|c|c|}
\hline EVENTO & ANO & $\begin{array}{l}\text { FORMAÇÃO DE } \\
\text { PROFESSORES }\end{array}$ & TÍTULO & AUTOR(ES) \\
\hline \multirow{3}{*}{ IX ENPEC } & \multirow{3}{*}{2013} & \multirow{2}{*}{$\begin{array}{l}\text { Formação } \\
\text { inicial }\end{array}$} & $\begin{array}{l}\text { Professores dos cursos de Biologia e } \\
\text { a (re)construção da nação brasileira a } \\
\text { partir da Lei no } 10.639 / 03\end{array}$ & Fernandes \\
\hline & & & $\begin{array}{l}\text { Discutindo questões raciais a partir } \\
\text { de uma poesia: uma análise das } \\
\text { interações discursivas }\end{array}$ & $\begin{array}{l}\text { Francisco } \\
\text { Júnior, Silva e } \\
\text { Yamashita }\end{array}$ \\
\hline & & $\begin{array}{l}\text { Formação } \\
\text { Continuada }\end{array}$ & $\begin{array}{l}\text { Diversidade e ensino de Ciências: } \\
\text { formação docente e pertencimento } \\
\text { racial }\end{array}$ & Verrângia \\
\hline
\end{tabular}

Fonte: Elaborado pelos autores deste artigo.

Os autores Francisco Júnior, Silva e Yamashita (2013), ao proporem a discussão da temática étnico-racial junto a uma turma de licencian- dos em Química, a partir de uma poesia que abordava o tema racismo, demonstraram que essa ação possui potencial para colaborar com 
o rompimento de práticas discriminatórias. A poesia “Lágrimas de Preta", de Antônio Gedeão (pseudônimo de Rómulo Vasco da Gama de Carvalho), traz alguns elementos que possibilitam fazer a ligação de alguns conhecimentos químicos e racismo. No entanto, quando o professor formador questiona os alunos para que analisem o poema, todos conseguiram identificar os conhecimentos da Química, mas dos 18 alunos que participaram da pesquisa, apenas um percebeu a possibilidades de discutir as relações étnico-raciais. Para os autores, isso pode estar diretamente associado à ausência de discussões sobre o tema na sociedade e no ensino de Ciências. A nosso ver, uma outra explicação, que não invalida a trazida pelos autores, está relacionada à dificuldade em perceber a inserção da relações étnico-raciais em disciplinas outras que não o Português, a História e as Artes, por exemplo. Assim, concordamos com Rocha e Aguiar (2012), que afirmam que para essa temática ser inserida na formação de professores de Ciências é necessário superar o mito de que só os professores de História e Letras são responsáveis por trabalhar essas questões em suas aulas.

Fernandes (2013) aborda a relação entre o conceito de nação e a Lei no 10.639 (BRASIL, 2003) entre os professores de Biologia, abordando a importância das contribuições dos outros povos para a constituição da nação brasileira e a necessidade dessa abordagem no ensino de Ciências. A autora faz uma reflexão sobre o termo nação, o qual define como "uma comunidade política, imaginada, soberana e limitada. Ao pensar na definição de nação como comunidade política, logo vem à mente disputa de poder" (FERNANDES, 2013, p. 2), defendendo que a forma como se entende o que é nação pode privilegiar a abordagem da história de alguns grupos e excluir a de outros, ou contar de maneira equivocada como aconteceu e acontece com a História da África e dos afrodescendentes. A autora considera ainda, que a Lei no 10.639/03, além de promover a História da África e dos afro- descendentes, favorece também a discussão sobre relações étnico-racial, e o combate ao racismo.

Em outro trabalho, Verrângia (2013) fez um estudo empírico cujo objetivo foi trabalhar o papel do pertencimento étnico-racial de docentes brasileiros e estadunidenses de Ciências e Biologia mediante processos educativos por eles vividos. 0 autor afirma que a prática docente pode ser compreendida como objeto de estudo sobre a discussão das relações étnico-raciais no entendimento das experiências vivenciadas pelos professores. Destaca ainda que "Os/as professores/as de Ciências têm de envolver-se no processo de expor ideologias racistas e desafiar sua própria prática, muitas vezes racista" (VERRÂNGIA, 2013, p. 7). 0 autor fala que o pertencimento racial interfere na prática pedagógica, porque para que a plena cidadania seja alcançada é necessário o envolvimento com as lutas por equidade travadas dentro dos grupos étnico-raciais.

Atualmente a formação de professores deve ter o objetivo de abordar temas sociais e não apenas conceitos específicos de determinada área do conhecimento. Partindo desse princípio, os processos formativos docentes devem se fundamentar na perspectiva da cidadania e, nesse contexto, é necessário abordar as relações étnico-raciais.

\section{Material didático}

Cinco trabalhos discutiram o livro didático, relações étnico-raciais e ensino de Ciências (área de Biologia), sendo três publicados em 2013, um em 2007 e um em 2015. Verrângia (2009), em sua pesquisa, mostrou que os professores não se sentem preparados para trabalhar essa temática em suas aulas, e um dos fatores seria a falta de material adequado, entre eles o livro didático é sempre citado. Outro aspecto sinalizado pelas autoras é que os negros pouco aparecem nos livros didáticos, e quando isso acontece, normalmente estão associados a lugares sociais desfavorecidos. 
Quadro 4 - Trabalhos sobre material didáticos para o ensino de Ciências, Química, Física e/ou Biologia com a temática étnico-racial

\begin{tabular}{|c|c|l|c|}
\hline EVENTO & ANO & \multicolumn{1}{|c|}{ TÍTUL0 } & AUTOR(ES) \\
\hline VI ENPEC & 2007 & $\begin{array}{l}\text { Raças biológicas e “raças humanas" em livros } \\
\text { didáticos de Biologia }\end{array}$ & Stelling e Krapas \\
\hline \multirow{2}{*}{ IX ENPEC } & 2013 & $\begin{array}{l}\text { Articulação entre conhecimento biológico e cultura } \\
\text { em livros didáticos: o que se ensina com a Biologia }\end{array}$ & Silva e Silva \\
\cline { 3 - 4 } & & $\begin{array}{l}\text { Estudos de racismo em livros didáticos e } \\
\text { perspectivas para investigar racismo científico em } \\
\text { livros de ciência }\end{array}$ & Castillo \\
\cline { 3 - 4 } & 2015 & $\begin{array}{l}\text { Dificuldades na aplicação de materiais Didáticos } \\
\text { digitais que trabalham assuntos estudados pela } \\
\text { Química em conformidade com a Lei no 10.639/03 }\end{array}$ & $\begin{array}{c}\text { Santos, Rodrigues } \\
\text { Filho e Amauro }\end{array}$ \\
\hline \multirow{2}{*}{ X ENPEC } & $\begin{array}{l}\text { Articulando Química, questões raciais e de gênero } \\
\text { numa Oficina sobre Diversidade desenvolvida } \\
\text { no âmbito do PIBID: análise da contribuição dos } \\
\text { recursos didáticos alternativos }\end{array}$ & $\begin{array}{c}\text { Santos, Siemsen e } \\
\text { Silva }\end{array}$ \\
\hline
\end{tabular}

Fonte: Elaborado pelos autores deste artigo.

A pesquisa de Silva e Silva (2013) destaca um processo de tendência para a homogeneização cultural, evidenciando como o processo de globalização tem proporcionado mudanças sociais que valorizam a cultura ocidental. Para nós, esses dados ratificam a necessidade de superar a centralização da cultura europeia, que não permite que se tornem visíveis os conhecimentos científicos de matriz africana. Além disso, as autoras defendem que "ao pensarmos a proposta de currículo único e a produção dos livros didáticos destinados a atender a todo o território nacional questionamos se a existência desse currículo nacional, de algum modo, não favorece processos de homogeneização" (SILVA; SILVA, 2013, p. 4).

Verrângia (2009), em sua pesquisa com professores brasileiros e estadunidenses, conclui que a maioria desses profissionais utilizam o livro didático como principal recurso. Os professores usam o livro e destacam sua importância, mas afirmam que nada os impede de consultar outras fontes como, por exemplo, a internet. $\mathrm{O}$ autor diz ainda que existem assuntos que são inevitáveis de serem apresentados, a exemplo, segundo os professores participantes da pesquisa, da ética, da postura e do profissionalismo, entre outros. Todos os participantes da pesquisa afirmaram que os livros não apresentam adequadamente a população negra, o que evidencia a necessidade de representações positivas sobre essa etnia nos livros didáticos.

Por fim, os dados deste levantamento revelam que além da pouca representatividade dessa temática no ENPEC, somente as disciplinas de Biologia, Ciências e Química têm contemplado discussões sobre as relações étnico-raciais. Tal fato deve ser problematizado porque a Lei no 10.639/03 (BRASIL, 2003) determina que estas questões devem ser contempladas por todas as disciplinas, e nesse contexto observamos a ausência de pesquisas envolvendo relações étnico-raciais e o ensino de Física.

\section{Considerações finais}

0 presente artigo trouxe um panorama sobre as discussões da temática étnico-racial, o que é uma contribuição importante para as pesquisas futuras sobre esse tema em razão da carência de trabalhos que nos mostrem em que medida as temáticas envolvendo a Lei $\mathrm{n}$ 은 10.639/03 (BRASIL, 2003) tem adentrado as instituições educadoras do Brasil. 
Outro aspecto importante se refere aos poucos trabalhos sobre as relações étnico-raciais e o ensino de Ciências, indicando a necessidade de mais pesquisas sobre a abordagem das relações étnico-raciais nas mais diversas áreas que envolvem o processo de ensino e aprendizagem. Destacamos a urgência em trabalhos na área de Física relacionados à Lei no $10.639 / 03$ (BRASIL, 2003), pois a ausência pode ser um indício das dificuldades que os educadores da área possuem em articular a Física com a temática.

\section{Referências}

ASSOCIAÇÃO BRASILEIRA DE PESQUISA EM EDUCAÇÃO EM CIÊNCIAS - ABRAPEC. ENPECS anteriores. Disponível em: http://abrapecnet.org. $\mathrm{br} /$ wordpress/pt/enpecs-anteriores/. Acesso em: 24 mar. 2018.

AZEVEDO, Maria Nizete; ABIB, Maria Lúcia V. S. Pesquisa-ação e a elaboração de saberes docentes em ciências. Investigações em Ensino de Ciências, Porto Alegre, v. 18, n. 1, p. 55-75, 2013. Disponível em: http://www.if.ufrgs.br/ienci/artigos/Artigo_ ID320/v18_n1_a2013.pdf. Acesso em: 03 nov. 2017.

BASTOS, Morgana Abranches; BENITE, Anna Maria Canavarro. Cultura africana e ensino de química: estudo sobre a formação docente. Revista da Associação Brasileira de Pesquisadores/as Negros/ as (ABPN), v. 9, n. 21, p. 64-80, 2017.

BRASIL. Ministério da Educação. Lei n o 10.639, de 09 de janeiro de 2003. Altera a Lei 9394/96 para incluir no currículo oficial da Rede de Ensino a obrigatoriedade da temática "História e cultura afro-brasileira”. Brasília, DF, 2003. Disponível em: http://portal.mec.gov.br/cne/arquivos/pdf/ res012003.pdf. Acesso em: 10 jun. 2017.

BRASIL. Ministério da Educação. Conselho Nacional de Educação. Conselho Pleno. Resolução CNE no 01, de 17 de junho de 2004. Institui Diretrizes Curriculares Nacionais para a Educação das Relações Étnico-Raciais e para o Ensino de História e Cultura Afro-Brasileira e Africana. Brasília, DF, 2004. Disponível em: http://portal.mec.gov.br/ cne/arquivos/pdf/res012004.pdf. Acesso em: 10 jun. 2017.

BRASIL. Ministério da Educação. Conselho Nacional de Educação. Conselho Pleno. Resolução CNE no
02, de 01 de julho de 2015. Define as Diretrizes Curriculares Nacionais para a formação inicial em nível superior (cursos de licenciatura, cursos de formação pedagógica para graduados e cursos de segunda licenciatura) e para a formação continuada. Brasília, DF, 2015. Disponível em: http://www.ead. unb.br/arquivos/geral/res_cne_cp_002_03072015. pdf. Acesso em: 04 set. 2017.

CARLAN, F. de A.; DIAS, M. S.; Preconceito étnico-racial: a escola, a ciência e a formação de professores. In: ENCONTRO NACIONAL DE PESQUISA EM EDUCAÇÃO EM CIÊNCIAS, 9., 2013, Águas de Lindóia, SP. Anais [...]. Águas de Lindóia, SP: ABRAPEC, 2013.

CASTILlO, María Juliana Beltrán. Estudos de racismo em livros didáticos e perspectivas para investigar racismo científico em livros de ciência. In: ENCONTRO NACIONAL DE PESQUISA EM EDUCAÇÃO EM CIÊNCIAS, 9., 2013, Águas de Lindoia, SP. Anais [...]. Águas de Lindoia, SP: Associação Brasileira de Pesquisa em Educação em Ciências (ABRAPEC), 2013.

CASTILLO, M. J. B.; ANDRADE, A. M. Estudos do racismo científico e da sociedade: perspectivas para a ação em ensino de ciências. In: ENCONTRO NACIONAL DE PESQUISA EM EDUCAÇÃO EM CIÊNCIAS, 10., 2015, Águas de Lindóia, SP. Anais [...]. Águas de Lindóia, SP: ABRAPEC, 2015.

COELHO, Wilma de Nazaré Baía; SOARES, Nicelma Josenila Brito. A implementação das leis $\mathrm{n}^{\circ}$ $10.639 / 2003$ e no $11.645 / 2008$ e o impacto na formação de professores: inflexão inicial. In: MÜLLER, T. M. P.; COELHO, W. de N. B.; FERREIRA, P. A. B. (org.). Relações étnico-raciais, formação de professores e currículo. São Paulo: Livraria da Física, 2015. p. 15-35.

DÁVILA, Jerry. As relações entre raça e estado no Brasil: contribuições para discussão no ensino de Biologia. In: DÁVILA, Jerry. Ensino de Biologia: conhecimentos e valores em disputa. Niterói, RJ: Editora da UFF, 2005. p. 17-36.

FERNADES, M. K. Professores dos cursos de Biologia e a (re)construção da nação brasileira a partir da Lei no 10.639/03. In: ENCONTRO NACIONAL DE PESQUISA EM EDUCAÇÃO EM CIÊNCIAS, 9., 2013, Águas de Lindóia, SP. Anais [...]. Águas de Lindóia, SP: ABRAPEC, 2013.

FRANCISCO JUNIOR, W. E.; SILVA, E. M. dos S.; YAMASHITA, M. Discutindo questões raciais a partir de uma poesia: uma análise das interações discursivas. In: ENCONTRO NACIONAL DE 
PESQUISA EM EDUCAÇÃO EM CIÊNCIAS, 9., 2013, Águas de Lindóia, SP. Anais [...]. Águas de Lindóia, SP: ABRAPEC, 2013.

GOMES, M. R; ROSA, K. D. Feminismos e ensino de ciências: histórico e implicações para aulas de física. In: SIMPÓSIO NACIONAL DE ENSINO DE FÍSICA, 21., 2015, Uberlândia, MG. Anais [...]. Uberlândia, MG: Sociedade Brasileira de Física, 2015.

GUIMARÃES, A. S. A. Como trabalhar com "raça" em sociologia. Educação \& Pesquisa, São Paulo, v. 29, n. 1, p. 93-107, 2003.

JESUS. Regina de Fátima. Dez anos da Lei $\mathbf{n}^{\circ}$ 10.639/03. Memórias e perspectivas. Fortaleza: Editora da Universidade Federal do Ceará, 2013.

JESUS, J; SANTOS, M. C.; PRUDÊNCIO, C. A. V. A Lei 10.639/03 e o ensino de Ciências: o que pensam os professores de Ciências das escolas estaduais de Itabuna/Bahia. Revista de Ensino de Biologia, n. 9, p. 1401-1411, 2016. Disponível em: http://www. sbenbio.org.br/blog/renbio-edicao-9/. Acesso em: 14 abr. 2017.

KRASILCHIK, M. O professor e o currículo das ciências. São Paulo: Edusp, 1987.

MELO, M. da C. C. 0 discurso da coordenação pedagógica da rede de ensino do município de Vicência sobre a noção de "raça". In: ENCONTRO NACIONAL DE PESQUISA EM EDUCAÇÃO EM CIÊNCIAS, 9., 2013, Águas de Lindóia, SP. Anais [...]. Águas de Lindóia, SP: ABRAPEC, 2013.

MOREIRA, P. F. da S. D.; AMAURO, N. Q.; RODRIGUES FILHO, G. Desvendando a anemia falciforme - uma proposta lúdica para aplicação da Lei Federal 10.639/03. In: ENCONTRO NACIONAL DE PESQUISA EM EDUCAÇÃO EM CIÊNCIAS, 9., 2013, Águas de Lindóia, SP. Anais [...]. Águas de Lindóia, SP: ABRAPEC, 2013.

MOREIRA, P. F. da S. D. et al. A bioquímica do candomblé - possibilidades didáticas de aplicação da Lei Federal 10.639/03. In: ENCONTRO NACIONAL DE PESQUISA EM EDUCAÇÃO EM CIÊNCIAS, 8., 2011, Campinas, SP. Anais [...]. Campinas, SP: ABRAPEC, 2011.

MUNANGA, Kabengele. Superando o racismo na escola. 2. ed. Brasília, DF: MEC/SECAD, 2005.

OLIVEIRA, Fátima. Saúde da população negra: Brasil ano 2001. Brasília, DF: Organização PanAmericana da Saúde (OPAS)/Secretaria Especial de Políticas de Promoção da Igualdade Racial, 2003.

OLIVEIRA, R. D. V. de.; TRINDADE, Y. R. D. A.;
QUEIROZ, G. R. P. C. O filme "Jardim das Folhas Sagradas" e a possibilidade de uma abordagem intercultural em aulas de ciências. In: ENCONTRO NACIONAL DE PESQUISA EM EDUCAÇÃO EM CIÊNCIAS, 9., 2013, Águas de Lindóia, SP. Anais [...]. Águas de Lindóia, SP: ABRAPEC, 2013.

PEDRANCINI, V. D.; CORAZZA, M. J. Raça ou espécie? Relações interpessoais em sala de aula. In. ENCONTRO NACIONAL DE PESQUISA EM EDUCAÇÃO EM CIÊNCIAS, 8., 2011, Campinas, SP. Anais [...]. Campinas, SP: ABRAPEC, 2011.

ROSA, Katemari. A (pouca) presença de minorias étnico-raciais e mulheres na construção da ciência. In: GARCIA, Marcos Dias; AUTH, Milton Antonio; TAKAHASHI, Kojy (Org.). Enfrentamentos do ensino de Física na sociedade contemporânea. São Paulo: Livraria da Física, 2016. p. 619-632.

ROCHA, Áurea Maria Costa; AGUIAR, Maria da Conceição Costa. Aprender a ensinar, construir identidade e profissionalidade docente no contexto da universidade: uma realidade possível. In: REUNIÃO ANUAL DA ANPEd, 35., 2012, Ipojuca, PE. Anais eletrônicos [...]. Ipojuca, PE: ANPEd, 2012. Disponível em: http://www.anped.org.br/ sites/default/files/gt08-1829_int.pdf. Acesso em: 14 abr. 2017.

SANTOS, E. da S.; RODRIGUES FILHO, G.; AMAURO, N. Q. Dificuldades na aplicação de materiais didáticos digitais que trabalham assuntos estudados pela química em conformidade com a Lei no 10.639/03. In: ENCONTRO NACIONAL DE PESQUISA EM EDUCAÇÃO EM CIÊNCIAS, 9., 2013, Águas de Lindóia, SP. Anais [...]. Águas de Lindóia, SP: ABRAPEC, 2013.

SANTOS, R. G. dos.; SIEMSEN, G. H.; SILVA, C. S. da. Articulando química, questões raciais e de gênero numa oficina sobre diversidade desenvolvida no âmbito do PIBID: análise da contribuição dos recursos didáticos alternativos. In: ENCONTRO NACIONAL DE PESQUISA EM EDUCAÇÃO EM CIÊNCIAS, 10., 2015, Águas de Lindóia, SP. Anais [...]. Águas de Lindóia, SP: ABRAPEC, 2015.

SILVA, Inayá Bittencourt. 0 racismo silencioso na escola pública. São Paulo: Uniara, 2009.

SILVA, Tadeu Tomaz. Documentos da identidade: uma introdução as teorias do currículo. 3. ed. Belo Horizonte: Autêntica, 2010.

SILVA, E. P. de Q.; SILVA, L. A. Articulação entre conhecimento biológico e cultura em livros didáticos: o que se ensina com a Biologia. In: 
ENCONTRO NACIONAL DE PESQUISA EM EDUCAÇÃO EM CIÊNCIAS, 2013, 9., Águas de Lindóia, SP. Anais [...]. Águas de Lindóia, SP: ABRAPEC, 2013.

SOUZA, Irene Sales. Os educadores e as relações interétnicas: pais e mestres. Franca, SP: Editora UNESP, 2001. v. 1.

STELLING, L. F. P.; KRAPAS, S. Raças biológicas e "raças humanas" em livros didáticos de biologia. In: ENCONTRO NACIONAL DE PESQUISA EM EDUCAÇÃO EM CIÊNCIAS, 6., 2007, Florianópolis. Anais [...]. Florianópolis: ABRAPEC, 2007.

TONÁCIO, G. de M. Et al. Raça, classe e etnia: o ensino das ciências na educação básica. In: ENCONTRO NACIONAL DE PESQUISA EM EDUCAÇÃO EM CIÊNCIAS, 10., 2015, Águas de Lindóia, SP. Anais [...]. Águas de Lindóia, SP: ABRAPEC, 2015.

VERRÂNGIA, Douglas. A educação das relações étnico-raciais no ensino de Ciências: diálogos possíveis entre Brasil e Estados Unidos. 2009. 332 f. Tese (Doutorado em) - Universidade Federal de São Carlos (UFSCar), São Carlos, SP, 2009.
VERRÂNGIA, Douglas. Diversidade e ensino de ciências: formação docente e pertencimento racial. In: ENCONTRO NACIONAL DE PESQUISA EM EDUCAÇÃO EM CIÊNCIAS, 9., 2013, Águas de Lindóia, SP. Atas... Águas de Lindóia, SP: ABRAPEC, 2013.

VERRÂNGIA, Douglas; SILVA, Petronilha Beatriz Gonçalves. Cidadania, relações étnico-raciais e educação desafios e potencialidades do ensino de Ciências. Educação e Pesquisa, São Paulo, v. 36, n. 3, p. 705-718, set./dez. 2010. Disponível em: http://www.scielo.br/pdf/ep/v36n3/v36n3a04. pdf. Acesso em: 01 mar. 2017.

VIEIRA, E. P. de P.; CHAVES, S. N. Diferenças raciais: o que diz a biologia, o que pensam os alunos. In: ENCONTRO NACIONAL DE PESQUISA EM EDUCAÇÃO EM CIÊNCIAS, 5., 2005, Bauru, SP. Anais [...]. Bauru, SP: ABRAPEC, 2005.

Recebido em: 03/02/2018

Aprovado em: 15/08/2019 